\title{
Glass as Radiation Sensor
}

\author{
Amany A. El-Kheshen \\ ${ }^{1}$ National Research Centre, Glass Research Department, \\ ${ }^{2}$ Chemistry Department, Faculty of Science, Taif University, \\ ${ }^{1}$ Egypt \\ ${ }^{2} \mathrm{KSA}$
}

\section{Introduction}

\subsection{What is glass? [Noel, 1998]}

Let's begin with what glass is not-it is not a crystal. The atoms in a crystal are organized in a regular, repetitive lattice so you need only locate a few atoms in order to predict where all of their neighbors are (Fig.1a). The atoms are so neatly arranged that, except for occasional crystal defects, you can predict positions for thousands or even millions of atoms in every direction. This spatial regularity is called long-range order.

(a)

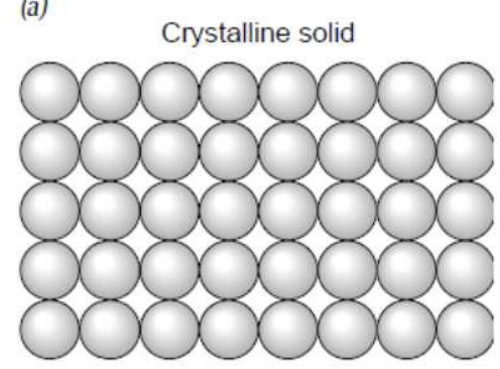

(b) Amorphous solid

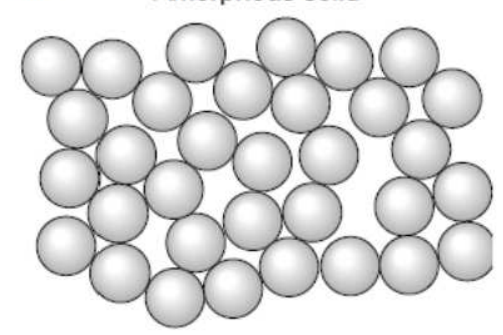

Fig. 1. (a), a crystalline solid with long-range order, (b), an amorphous solid, no long-range order. 
Glass is an amorphous solid, a material without long-range order (Fig. 1b). Locating a few glass atoms tells you nothing about where to find any other atoms. The atoms in glass are arranged in the random manner of a liquid because glass is essentially a super-stiff liquid. Its atoms are jumbled together in a sloppy fashion but they can't move about to form a more orderly arrangement. Glass arrives at this peculiar amorphous state when hot liquid glass is cooled too rapidly. If molten glass were an ordinary liquid, it would begin to solidify abruptly during cooling once it reached its freezing temperature. At that point, its atoms would begin to arrange themselves in crystals that would grow in size until there was no liquid left. That's what's normally meant by freezing. However some liquids are slow to crystallize when you cool them slightly below their freezing temperatures. While they may be cold enough to grow crystals, they must get those crystals started somehow. If crystallization doesn't start, material's atoms and molecules will continue to move about and it will behave as a liquid. When that happens, the liquid is said to be supercooled. Supercooling is common in liquids that have difficulties forming the initial seed crystals on which the rest of the liquid can crystallize. Because almost all of the atoms in a seed crystal are on its surface, it has a relatively large surface tension and surface energy. Below a certain critical size, a crystal is unstable and tends to fall apart rather than grow. However once the first seed crystals manage to form, a process called nucleation, the rest of the supercooled liquid may crystallize with startling rapidity. Just below its freezing temperature, the atoms in glass don't bind to one another long enough to form complete seed crystals, and nucleation takes almost forever. At somewhat lower temperatures, seed crystals begin to nucleate, but glass's large viscosity (thickness) prevents these crystals from growing quickly. The glass remains a supercooled liquid for an unusually long time. At even lower temperatures, glass becomes so viscous that crystal growth stops altogether. The glass is then a stable supercooled liquid. At this temperature range, glass still pours fairly easily and can be stretched or molded into almost any shape.

However, when you cool the glass still further, it becomes a glass. Here the word glass refers to a physical state of the material - a type of amorphous solid. To distinguish this use of the word glass from the common building material, it is italicized. Glass, the material, becomes a glass, the state, at the glass transition temperature (Tg). Below $\mathrm{Tg}$, the atoms in the glass rarely move past one another; they continue to jiggle about with thermal energy but they don't travel about the material.

\subsection{A quick journey with glass [Gerry, M., 2002]}

The production of glass has been occurring naturally for millions of years, but the discovery of manufactured glass leads us to live a luxury life.

Natural glass has existed since the beginnings of time, formed when certain types of rocks melt as a result of high-temperature phenomena such as volcanic eruptions, lightning strikes or the impact of meteorites and then cool and solidify rapidly. The earliest man-made glass objects, mainly non-transparent glass beads, are thought to date back to around 3500 B.C., which found in Egypt. Phoenician merchants and sailors spread this new art along the coasts of the Mediterranean Sea.

After 1500 B.C., Egyptian craftsmen are known to have begun developing a method for producing glass pots by dipping a core mould of compacted sand into molten glass and then turning the mould so that molten glass adhered to it. While still soft, the glass-covered mould could then be rolled on a slab of stone in order to smooth or decorate it. The earliest 
examples of Egyptian glassware are three vases bearing the name of the Pharaoh Thoutmosis 2I (1504-1450 B.C.).

The first instance of glass being used for windows in buildings, especially in Britain, was during the period of the Romans. In the 1st century A. D., it is known that the Romans used glass for a variety of reasons including mosaic tiles, decorating pottery and as windows. It seems that the glass window became more popular with the advent of churches and other places to worship. Most of the earliest examples of Roman window glass are colored, suggesting that they were glass windows for churches, for example. Around the world, the need for glass windows (and the manufacture of the glass) did not really take hold until the 11 th century.

\subsection{It only looks like magic (A world of glass) \\ 1.3.1 First types of glass}

The first types of glass invented centuries ago, scientists made that glass by mixing materials, melting and then cooling to form a solid. There are many different types of glass with different chemical and physical properties. Each can be made by a suitable adjustment to chemical compositions, but the main types of glass are:

- Commercial Glass also known as soda-lime glass

- $\quad$ Lead Glass

- $\quad$ Borosilicate Glass

- Glass Fiber

Glasses may be devised to meet almost any imaginable requirement. For many specialized applications in chemistry, pharmacy, the electrical andelectronics industries, optics, or the comparatively family of materials known as glass ceramics? Glass is a practical material for the engineer to use.

\subsubsection{Commercial glass}

Most of the glass we see around us in our everyday lives in the form of bottles and jars, flat glass for windows or for drinking glasses is known as commercial glass or soda-lime glass, as soda ash is used in its manufacture.

The main constituent of practically all commercial glass is sand. Sand by itself can be fused to produce glass but the temperature at which this can be achieved is $\geq 1700 \mathrm{oC}$. Adding other minerals and chemicals to sand can considerably reduce the melting temperature.

The addition of sodium carbonate (Na2CO3), known as soda ash, to produce a mixture of $75 \%$ silica $(\mathrm{SiO} 2)$ and $25 \%$ of sodium oxide $(\mathrm{Na} 2 \mathrm{O})$, will reduce the temperature of fusion to about $800 \mathrm{oC}$. However, a glass of this composition is water-soluble and is known as water glass. In order to give the glass its stability, other chemicals like calcium oxide $(\mathrm{CaO})$ and magnesium oxide $(\mathrm{MgO})$ are needed.

Commercial glass is normally colorless, allowing it to freely transmit light, which is what makes glass ideal for windows and many other uses. Additional chemicals have to be added to produce different colors of glass.

Most of commercial glasses have roughly similar chemical compositions of:

$70 \mathrm{wt} \%-74 \mathrm{wt} \% \mathrm{SiO} 2$ (silica)

$12 \mathrm{wt} \%-16 \mathrm{wt} \% \mathrm{Na} 2 \mathrm{O}$ (sodium oxide)

$5 w t \%-11 w t \% \mathrm{CaO}$ (calcium oxide)

$1 \mathrm{wt} \%-3 \mathrm{wt} \% \mathrm{MgO}$ (magnesium oxide)

$1 w t \%-3 w t \%$ Al2O3 (aluminium oxide) 
Flat glass is similar in composition to container glass except that it contains a higher proportion of magnesium oxide.

Within these limits the composition is varied to suit a particular product and production method. The raw materials are carefully weighed and thoroughly mixed, as consistency of composition is of utmost importance in making glass.

Nowadays, recycled glass from bottle banks collections, known as cullet, is used to make new glass. Using cullet has many environmental benefits, it prevents pollution by reducing quarrying, and because cullet melts more easily, it saves energy.

Almost any proportion of cullet can be added to the mix (known as batch), but in the right condition. Although the recycled glass may come from manufacturers around the world, it can be used by any glassmaker, as the container glass compositions are very similar. It is however important, that glass colors are not mixed and that the cullet is free from impurities, especially metals and ceramics.

\subsubsection{Lead glass}

Commonly known as lead crystal, lead glass is used to make a wide variety of decorative glass objects.

It is made by using lead oxide instead of calcium oxide, and potassium oxide instead of all or most of the sodium oxide. The traditional English full lead crystal contains at least 30\% lead oxide $(\mathrm{PbO})$ but any glass containing at least $24 \% \mathrm{PbO}$ can be described as lead crystal. Glass containing less than $24 \% \mathrm{PbO}$, is known simply as crystal glass. The lead is locked into the chemical structure of the glass so there is no risk to human health.

Lead glass has a high refractive index making it sparkle brightly and a relatively soft surface so that it is easy to decorate by cutting and engraving which highlights the crystal's brilliance making it popular for glasses, decanters and other decorative objects.

Glass with even higher lead oxide contents (typically 65\%) may be used as radiation shielding because of the well-known ability of lead to absorb gamma rays and other forms of harmful radiation.

\subsubsection{Borosilicate glass}

Most of us are more familiar with this type of glass in the form of ovenware and other heatresisting ware, better known under the trade name Pyrex.

Borosilicate glass, the third major group, is made mainly of silica (70-80wt \%) and boric oxide (7-13wt \%) with smaller amounts of the alkalis (sodium and potassium oxides) and aluminum oxide. This type of glass has relatively low alkali content and consequently has good chemical durability and thermal shock resistance. As a result it is widely used in the chemical industry, for laboratory apparatus, for ampoules and other pharmaceutical containers and as glass fibers for textile and plastic reinforcement.

\subsubsection{Glass fiber}

Glass fiber has many uses from roof insulation to medical equipment and its composition varies depending on its application.

For building insulation, the type of glass used is normally soda lime. For textiles, an alumino-borosilicate glass with very low sodium oxide content is preferred because of its good chemical durability and high softening point. This is also the type of glass fiber used in the reinforced plastics to make protective helmets, boats, piping, car chassis, ropes, car exhausts and many other items. 
In recent years, great progress has been made in making optical fibers which can guide light and thus transmit images round corners. These fibers are used in endoscopes for examination of internal human organs, changeable traffic message signs now on motorways for speed restriction warnings and communications technology, without which telephones and the internet would not be possible.

\subsubsection{Special glass}

Types of special glass change according to human needs and development. Earlier, the special types of glass were:

- Vitreous silica

- Aluminosilicate glass

- Alkali-barium silicate glass

- Technical Glass

- Glass Ceramics

- Optical glass

- $\quad$ Sealing glass

\subsubsection{Vitreous silica glass}

Silica glass or vitreous silica is of considerable technical importance as it has a very low thermal expansion. This glass contains tiny holes and is used for filtration. Porous glasses of this kind are commonly known as Vycor.

\subsubsection{Alumino-silicate glass}

An important type of glass, aluminosilicate, contains $20 \mathrm{wt} \%$ aluminium oxide (alumina$\mathrm{Al2O} 3$ ), often including calcium oxide, magnesium oxide and boric oxide in relatively small amounts, with very small amounts of soda or potash. It is able to withstand high temperatures and thermal shock and is typically used in combustion tubes, gauge glasses for high-pressure steam boilers, and in halogen-tungsten lamps capable of operating at temperature as high as $750^{\circ} \mathrm{C}$.

\subsubsection{Alkali-barium silicate glass}

Without this type of glass, watching TV would be very dangerous. A television produces Xrays that must be absorbed; otherwise they could in the long run cause health problems. The X-rays are absorbed by glass with minimum amounts of heavy oxides (lead, barium or strontium). Lead glass is commonly used for the funnel and neck of the TV tube, while glass containing barium is used for the screen.

\subsubsection{Technical glass}

Technical is the term given to a range of glasses used in the electronics industry.

Without borate glass, the computer revolution would not have been possible as it's vitally important in producing electrical components. This type of glass contains little or no silica and is used for soldering glass, metals or ceramics as it melts at the relatively low temperature (450-550oC), below that of normal glass, ceramics and many metals.

Glass of a slightly different composition is used for protecting siliconsemi-conductor components against chemical attack and mechanical damage, known as passivation glass.

Chalcogenide glass, similar semi conductor effect, is a type of glass that can be made without the presence of oxygen. Some of them have potential use as infrared transmitting materials and as switching devices in computer memories because their conductivity changes abruptly when particular voltage values are exceeded. 


\subsubsection{Glass ceramic}

Some of these "Glass ceramics", formed typically from lithium aluminosilicate glass, are extremely resistant to thermal shock and have found several applications where this property is important, including cooking ware, mirror substrates for astronomical telescopes and missile nose cones.

An essential feature of glass is that it does not contain crystals. However, by deliberately stimulating crystal growth in glass, it is possible to produce a type of glass with a controlled amount of crystallization that can combine many of the best features of ceramics and glass.

\subsubsection{Optical glass}

Optical glasses are found in scientific instruments, microscopes, and fighter aircraft and most commonly in spectacles.

The most important properties are the refractive index and the dispersion. The index is a measure of how much the glass bends light. The dispersion is a measure of the way the glass splits white light into the colors of the rainbow. Glass makers use the variations in these characteristics to develop optical glasses.

\subsubsection{Sealing glass}

A wide variety of glass compositions are used to seal metals for electrical and electronic components. Here the available glasses may be grouped according to their thermal expansion which must be matched with the thermal expansions of the respective metals so that sealing is possible without excessive strain being induced by differing levels of expansion.

For sealing to tungsten, in making incandescent and discharge lamps, borosilicate alkaline earths or aluminous silicate glasses are suitable. Sodium borosilicate glasses may be used for sealing to molybdenum and the iron-nickel-cobalt (Fernico) alloys, are frequently employed as a substitute. The amount of sodium oxide permissible depending on the degree of electrical resistance required. With glasses designed to seal to Kovar alloy, relatively high contents of boric oxide (approximately 20\%) are needed to keep the transformation temperature low and usually the preferred alkali is potassium oxide so as to ensure high electrical insulation.

Where the requirement for electrical insulation is paramount, as in many types of vacuum tube and for the encapsulation of diodes, a variety of lead glasses (typical containing between $30 \%$ and $60 \%$ lead oxide) can be used.

\subsubsection{Colored glase (Weyl, 1959)}

Color is the most obvious property of a glass object. It can also be one of the most interesting and beautiful properties. Although color rarely defines the usefulness of a glass object it almost always defines its desirability.

\subsection{The colored glass recipe}

The earliest people who worked with glass had no control over its color. Then, through accident and experimentation glass makers learned that adding certain substances to the glass melt would produce spectacular colors in the finished product. Other substances were discovered that, when added to the melt, would remove color from the finished project.

The Egyptians and the Romans both became expert at the production of colored glass. In the eighth century, an Arab chemist known as "Gerber" recorded dozens of formulas for the production of glass in specific colors. Gerber is often known as the "father of chemistry" and he realized that the oxides of metals were the key ingredients for coloring glass. 


\subsection{The glass color palette}

Once the methods of colored glass production was discovered, an explosion of experimentation began. The goal was to find substances that would produce specific colors in the glass. Some of the earliest objects made from glass were small cups, bottles and ornaments.

Religious organizations were among those who provided incentive to the early glass artisans. Stained glass windows became very popular additions to churches and mosques over 1000 years ago. These artists needed a full palette of colors to make a realistic stained glass scene. This search for a full palette fueled research and experimentation to produce a vast array of colors.

\subsection{Colors of duration}

Then, another problem was discovered. Many of the glass colors did not stand up to year-in, year-out exposure to the direct rays of the sun. The result was a stained glass scene of deteriorating beauty. Some colors darkened or changed over time, while others faded away. Research and experimentation continued in an effort to meet the need for colors of duration. Eventually a full palette of fairly stable colors was achieved.

\section{I.3.2.8.4 Metals used to color glass}

The recipe for producing colored glass usually involves the adding of a metal to the glass. This is often accomplished by adding some powdered oxide, sulfide or other compound of that metal to the glass while it is molten. The table below lists some of the coloring agents of glass and the colors that they produce. Manganese dioxide and sodium nitrate are also listed. They are discoloring agents - materials that neutralize the coloring impact of impurities in the glass.

\begin{tabular}{ll} 
Metals Used to Impart Color to Glass & \\
Yellow & Cadmium Sulfide \\
Red & Gold Chloride \\
Blue-Violet & Cobalt Oxide \\
Purple & Manganese Dioxide \\
Violet & Nickel Oxide \\
Yellow-Amber & Sulfur \\
Emerald Green & Chromic Oxide \\
Fluorescent Yellow, Green & Uranium Oxide \\
Greens and Browns & Iron Oxide \\
Reds & Selenium Oxide \\
Amber Brown & Carbon Oxides \\
White & Antimony Oxides \\
Blue, Green, Red & Copper Compounds \\
White & Tin Compounds \\
Yellow & Lead Compounds \\
A "decoloring" agent & Manganese Dioxide \\
A "decoloring" agent & Sodium Nitrate \\
\hline
\end{tabular}

Table 1. 


\subsection{What types of radiation are there?}

The radiation one typically encounters is one of four types: alpha radiation, beta radiation, gamma radiation, and $x$ radiation. Neutron radiation is also encountered in nuclear power plants and high-altitude flight and emitted from some industrial radioactive sources.

\subsubsection{Alpha radiation}

Alpha radiation is a heavy, very short-range particle and is actually an ejected helium nucleus. Some characteristics of alpha radiation are:

Most alpha radiation is not able to penetrate human skin.

Alpha-emitting materials can be harmful to humans if the materials are inhaled, swallowed, or absorbed through open wounds.

A variety of instruments has been designed to measure alpha radiation. Special training in the use of these instruments is essential for making accurate measurements.

A thin-window Geiger-Mueller (GM) probe can detect the presence of alpha radiation. Instruments cannot detect alpha radiation through even a thin layer of water, dust, paper, or other material, because alpha radiation is not penetrating.

Alpha radiation travels only a short distance (a few inches) in air, but is not an external hazard. Alpha radiation is not able to penetrate clothing. Examples of some alpha emitters: radium, radon, uranium, thorium.

\subsubsection{Beta radiation}

Beta radiation is a light, short-range particle and is actually an ejected electron. Some characteristics of beta radiation are:

Beta radiation may travel several feet in air and is moderately penetrating.

Beta radiation can penetrate human skin to the "germinal layer," where new skin cells are produced. If high levels of beta-emitting contaminants are allowed to remain on the skin for a prolonged period of time, they may cause skin injury.

Beta-emitting contaminants may be harmful if deposited internally.

Most beta emitters can be detected with a survey instrument and a thin-window GM probe (e.g., "pancake" type). Some beta emitters, however, produce very low-energy, poorly penetrating radiation that may be difficult or impossible to detect. Examples of these difficult-to-detect beta emitters are hydrogen-3 (tritium), carbon-14, and sulfur-35.

Clothing provides some protection against beta radiation. Examples of some pure beta emitters: strontium-90, carbon-14, tritium, and sulfur-35.

\subsubsection{Gamma and X- radiation}

Gamma radiation and $\mathrm{x}$ rays are highly penetrating electromagnetic radiation. Some characteristics of these radiations are:

Gamma radiation or $x$ rays are able to travel many feet in air and many inches in human tissue. They readily penetrate most materials and are sometimes called "penetrating" radiation.

$\mathrm{X}$ rays are like gamma rays. $\mathrm{X}$ rays, too, are penetrating radiation. Sealed radioactive sources and machines that emit gamma radiation and $x$ rays respectively constitute mainly an external hazard to humans.

Gamma radiation and $x$ rays are electromagnetic radiation like visible light, radio waves, and ultraviolet light. These electromagnetic radiations differ only in the amount of energy they have. Gamma rays and $x$ rays are the most energetic of these. 
Dense materials are needed for shielding from gamma radiation. Clothing provides little shielding from penetrating radiation, but will prevent contamination of the skin by gammaemitting radioactive materials.

Gamma radiation is easily detected by survey meters with a sodium iodide detector probe. Gamma radiation and/or characteristic $x$ rays frequently accompany the emission of alpha and beta radiation during radioactive decay.

Examples of some gamma emitters: iodine-131, cesium-137, cobalt-60, radium-226, and technetium-99m.

\section{Effect of radiation on different types of glass}

\subsection{Silicate glass}

Jiawei Shenga (2009) studied the effect of UV-laser irradiation on the soda-lime silicate glass by preparing Commercial soda-lime silicate glass substrates composed of (wt \%): 73.2 $\mathrm{SiO}_{2}, 15.3 \mathrm{Na}_{2} \mathrm{O}, 1.3 \mathrm{Al}_{2} \mathrm{O}_{3}$, and $10.2 \mathrm{CaO}$, they found that As shown in Fig. 1, the asquenched base glass was colorless and had no measurable absorptions in the visible region. In addition, no ESR signal was observed in the blank samples. After laser irradiation, two characteristic absorption bands in the visible region with maxima at about 620 , and $430 \mathrm{~nm}$, respectively, were observed. More precise peak positions were determined to be 627 and 431 $\mathrm{nm}$ for these two bands, respectively, with the assistance of Gaussian resolution [Friebele 1991, Marshall 1997, Zhang 2007] (Fig. 2,). As a result, the glass showed slight brown. The induced color was unstable, as indicated by the decease of the peak intensity after $50 \mathrm{~h}$ room temperature storage following the irradiation (Fig. 2). These results were similar to the case using X-ray radiation [Sheng, 1970]. Radiation may cause the displacement of lattice atoms or electron defects that involve changes in the valence state of lattice or impurity atoms. The ionizing radiation produces electron-hole pairs in the glass structure. Accordingly, new optical absorption bands were developed [Sheng, 1970]. In general, these absorptions are associated with either oxygen deficiency or oxygen excess in the glass network. The most fundamental radiation-induced defects in glass are the nonbridging oxygen hole center $\left(\mathrm{NBOHC}:{ }^{\wedge} \mathrm{Si}-\mathrm{O}^{*}\right)$, the $\mathrm{E}^{\prime}$ center $\left({ }^{\wedge} \mathrm{Si}^{*}\right)$, the peroxy radical $\left(\mathrm{POR}:{ }^{\wedge} \mathrm{Si}-\mathrm{O}-\mathrm{O}^{*}\right)$, and the trapped electrons (TE), where the notation " $\wedge$ " represents three bonds with other oxygen in the glass network and " $" *$ " denotes an unpaired electron. According to current knowledge, absorption bands of 627 and $431 \mathrm{~nm}$ in the soda-lime silicate glass were identified mainly as absorption of NBOHCs [Bishay, 1970, Wong, 1967, Sheng, 2007]. The main absorptions of the E0 center and the POR are in the far UV region, which have less effect on the glass visible color. Fig. 3 shows the ESR spectrum of the glass after the irradiation. Two distinctive signals at $\mathrm{g}^{1 / 4}$ $1.99 w 2.00$ and $g$ 1/4 1.992, respectively, were observed. As expected, the $g$ 1/4 1.99w2.00 was identified as the defects of NBOHCs, correlating bands of 627 and $431 \mathrm{~nm}$. The signal of $\mathrm{g} 1 / 4$ 1.992 might attribute to the defect of $E^{\prime}$ center. The spectra of the induced absorption with varying exposure time are presented in Fig. 4 . The peak heights of the induced absorption increased with the laser irradiation time, and the peak positions absorption band were relatively constant, suggesting that only variations of their populations of defects be effected by the irradiation time. As shown in Fig. 4 (insert), the absorptions at 627 or $431 \mathrm{~nm}$ increased rapidly during the first $30 \mathrm{~min}$ radiation. The increase was then slow down and no more increase was observed after $60 \mathrm{~min}$ radiation. Irradiation energy is another important factor that affects the induced absorption of glass. As can be seen in Fig. 5, the induced absorption increased when the energy density was increased, while the induced absorption peak positions were relatively constant. 


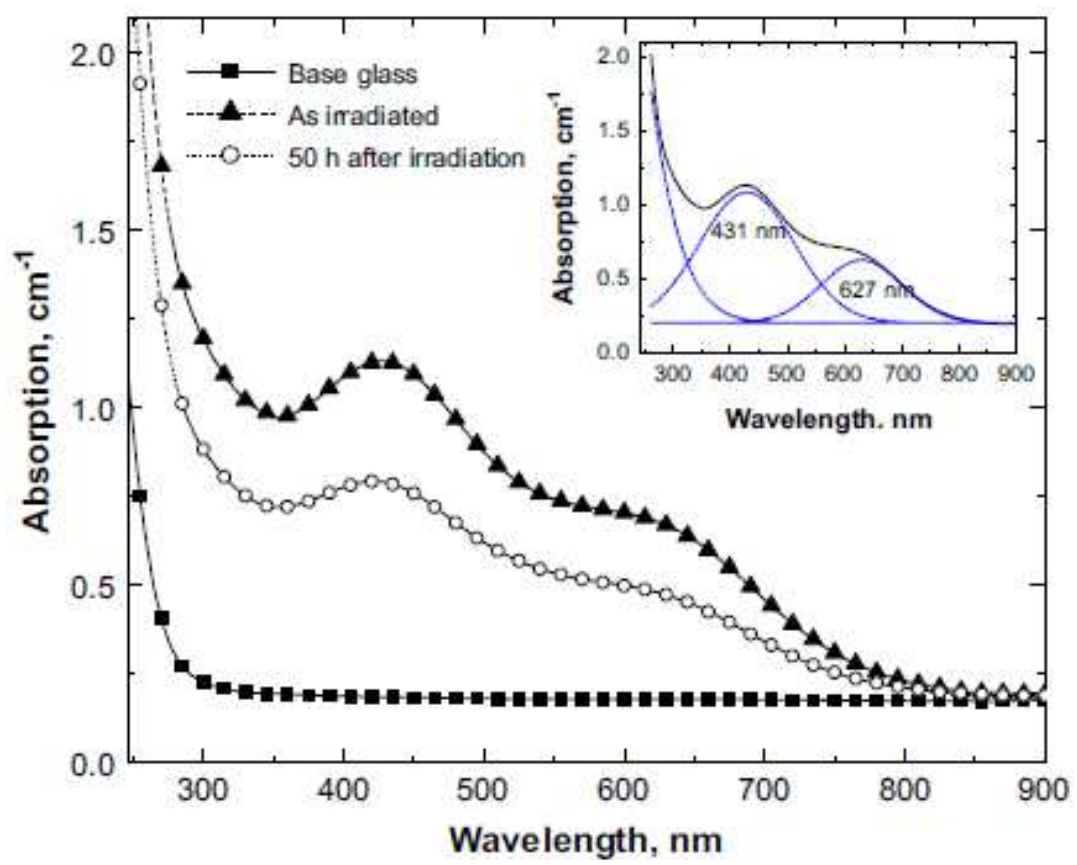

Fig. 2. Optical absorption in soda-lime silicate glass after UV-laser irradiation at $75 \mathrm{~mJ} / \mathrm{cm}^{2}$ for $10 \mathrm{~min}$ (insert Gaussian resolution of induced absorption)

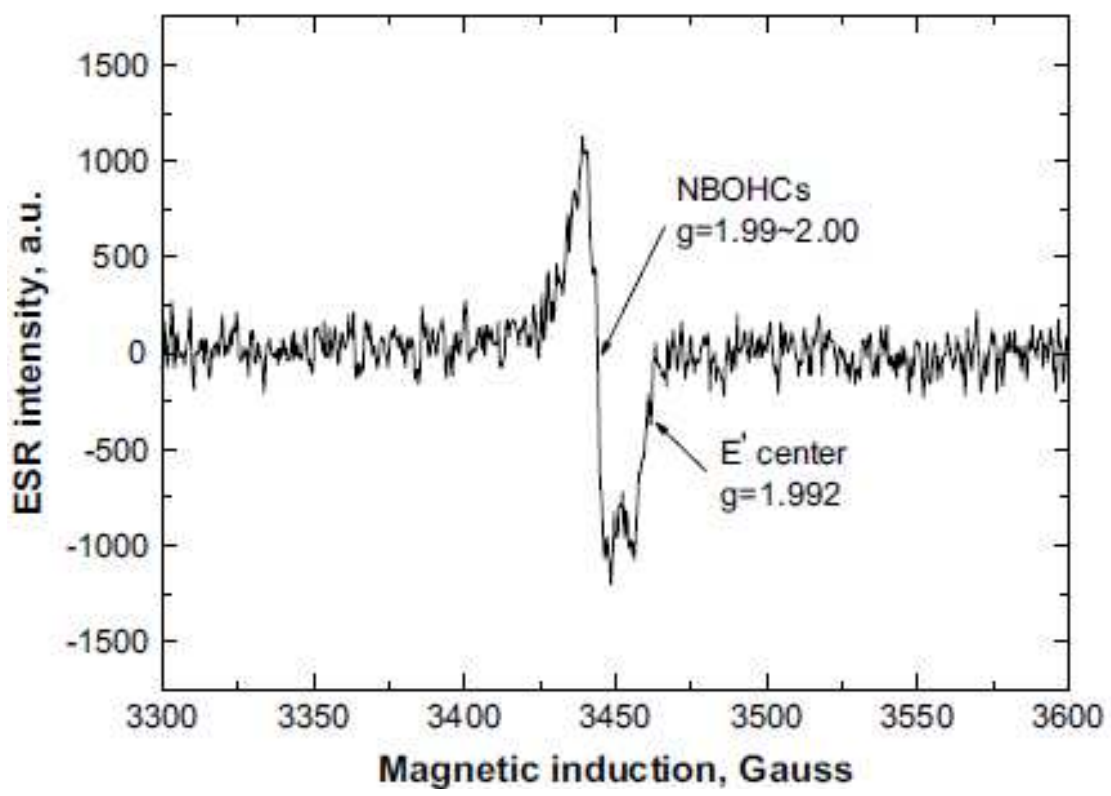

Fig. 3. ESR spectra of glass after irradiation at $75 \mathrm{~mJ} / \mathrm{cm}^{2}$ for $10 \mathrm{~min}$ 


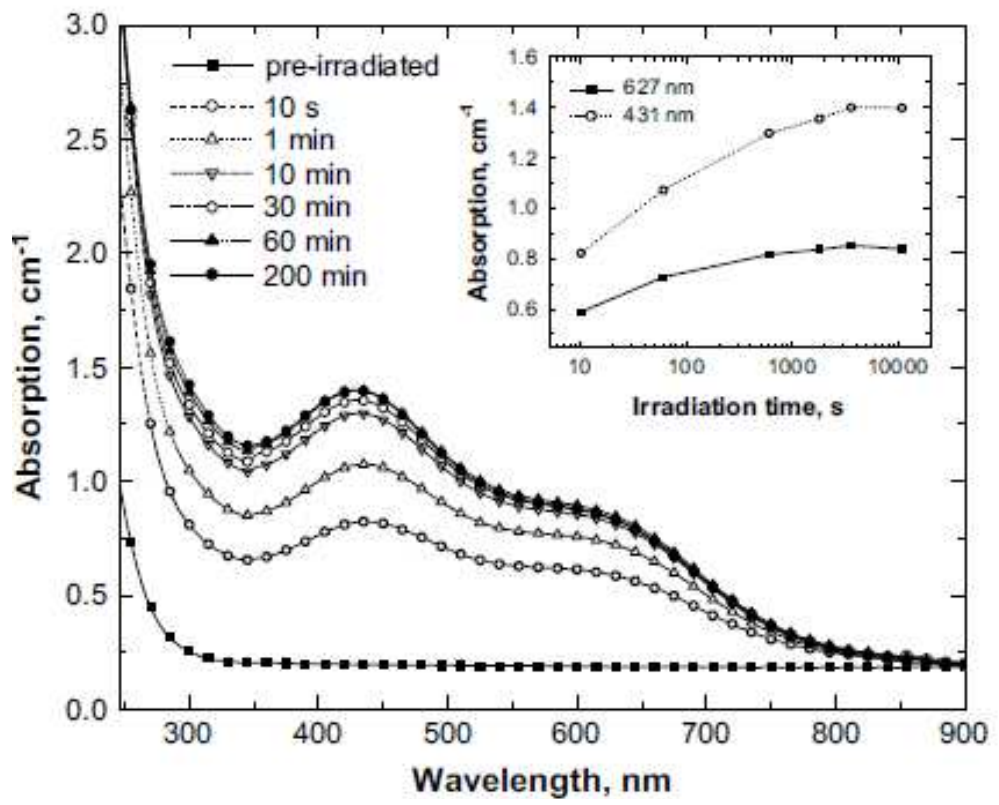

Fig. 4. Radiation induced optical Absorption with varied irradiation time $\left(75 \mathrm{~mJ} / \mathrm{cm}^{2}\right)$ (insert: Optical absorptions affected by irradiation time)

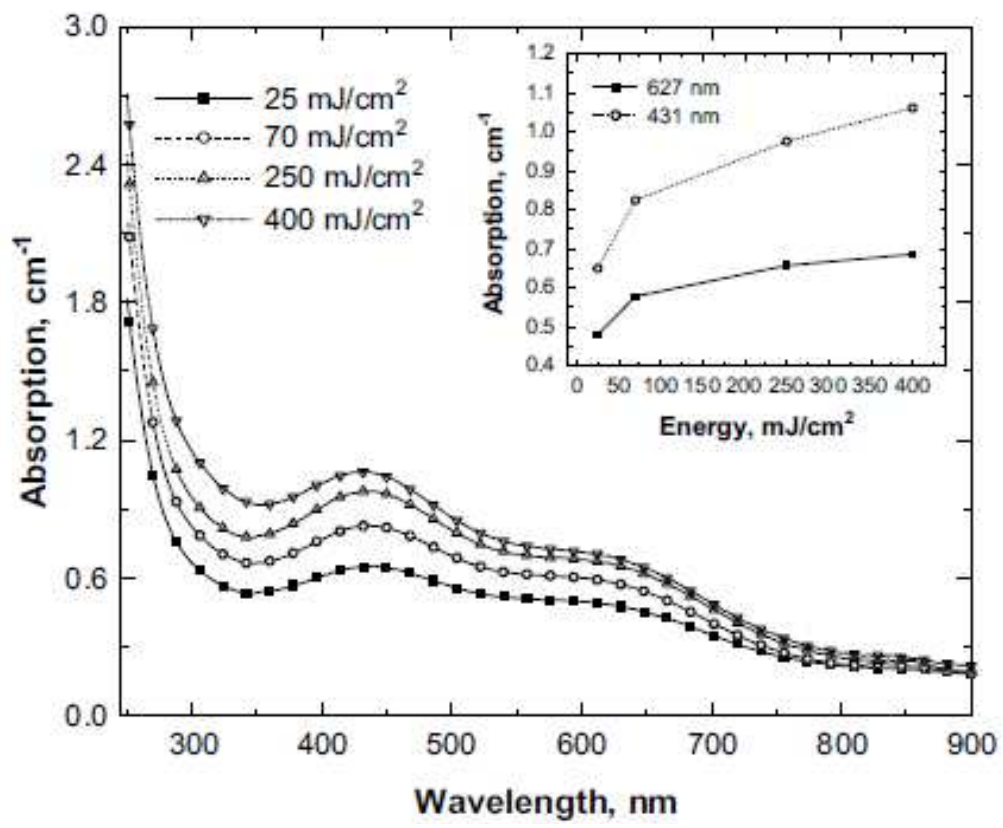

Fig. 5. Optical absorption affected by irradiation energy (100 shots) (insert: Optical absorption affected by irradiation energy). 
Gusarov et al (2010) studied the effect of gamma irradiation on Silica-soda-lime glass with a composition $75 \mathrm{SiO}_{2}-22 \mathrm{Na}_{2} \mathrm{O}-3 \mathrm{CaO}$, wt. \% (labelled R1) and the same glass doped with 0.05 wt. $\% \mathrm{CeO}_{2}$ (labelled R7) were melted from high purity raw components using a technology which allowed one to keep the concentration of impurities of Fe ions at a few ppm and other transition metals below $1 \mathrm{ppm}$. Experimental samples were prepared as plates $25 \times 25 \mathrm{~mm} 2$, $\sim 1 \mathrm{~mm}$ thick, and polished for optical measurements. The glass samples contained a small number of air bubbles with diameters up to $\sim 0.1 \mathrm{~mm}$, however transmission measurements at different parts on several samples showed that their influence was below the detection level. All transmission spectra were measured from 195 to $3300 \mathrm{~nm}$ with a commercial double-beam UV-Vis-NIR spectrophotometer. Irradiations have been performed in the Brigitte gamma irradiation facility at SCK CEN at 70, 200, and $350 \circ \mathrm{C}, 25 \mathrm{kGy} / \mathrm{h}$. They found that the addition of $\mathrm{CeO}_{2}$ results in significant transmission degradation in the UV (Fig. 6)

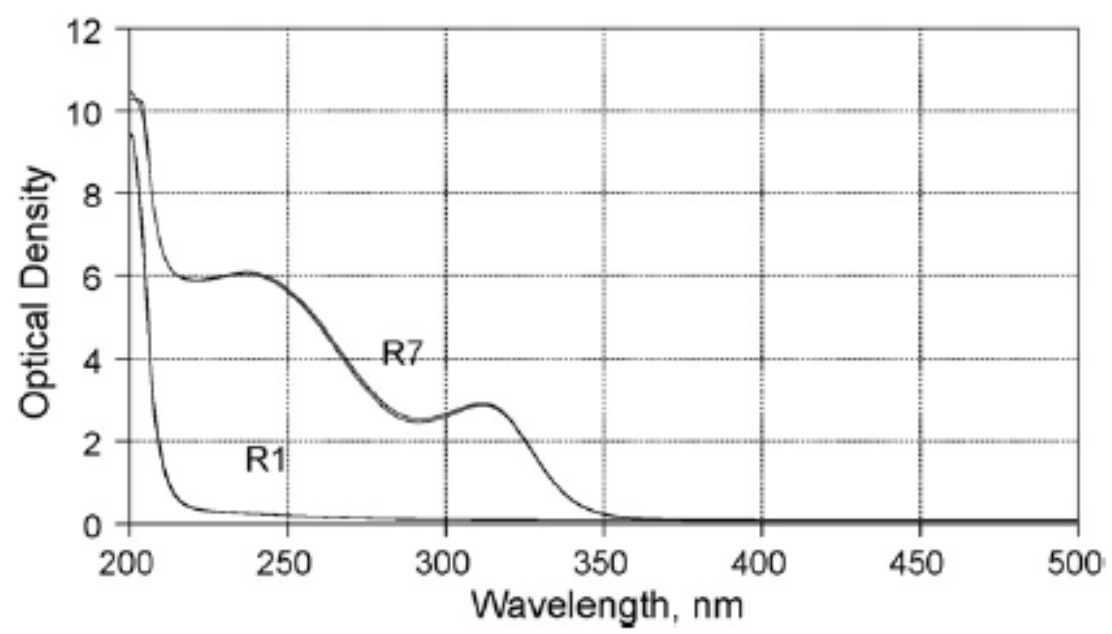

Fig. 6. Optical absorption spectra of R1-5 and R7-5 glass samples in the UV range. For each glass two spectra are plotted: before and after annealing for $24 \mathrm{~h}$ at $350 \circ \mathrm{C}$

This degradation is due to the overlapping optical absorption bands of $\mathrm{Ce}^{3+}$ and $\mathrm{Ce}^{4+}$ ions, with maxima at 313 and $240 \mathrm{~nm}$ (3.96 and $5.15 \mathrm{eV})$, respectively [Arbuzov, 1990]. Above 350 $\mathrm{nm}$ both materials show the same high transmission with no observable optical absorption bands. No detectable changes in transmission were observed after annealing R1 and R7 control glass samples for $24 \mathrm{~h}$ at $200{ }^{\circ} \mathrm{C}$. Annealing for 24 at $350{ }^{\circ} \mathrm{C}$ does not change the transmission of R1. For R7 a weak band with amplitude of $\sim 0.3 \mathrm{~cm}-1$ at 275 unappeased. This effect can be tentatively attributed to thermally-stimulated charge transfer between Ce and Fe ions. However, the amplitude of this thermally induced band is significantly less than the amplitude of bands produced by irradiation.

\subsection{Phosphate glass doped with cobalt oxide}

Sodium phosphate glass with different $\mathrm{CoO}$ percentage was prepared [El-Batal, 2010], A 60Co gamma cell $(2000 \mathrm{Ci})$ was used as a c- ray source with a dose rate of $1.5 \mathrm{~Gy} / \mathrm{s}$ (150 rads/s) at a room temperature of $\sim 30^{\circ} \mathrm{C}$. The investigated glass samples were subjected to 

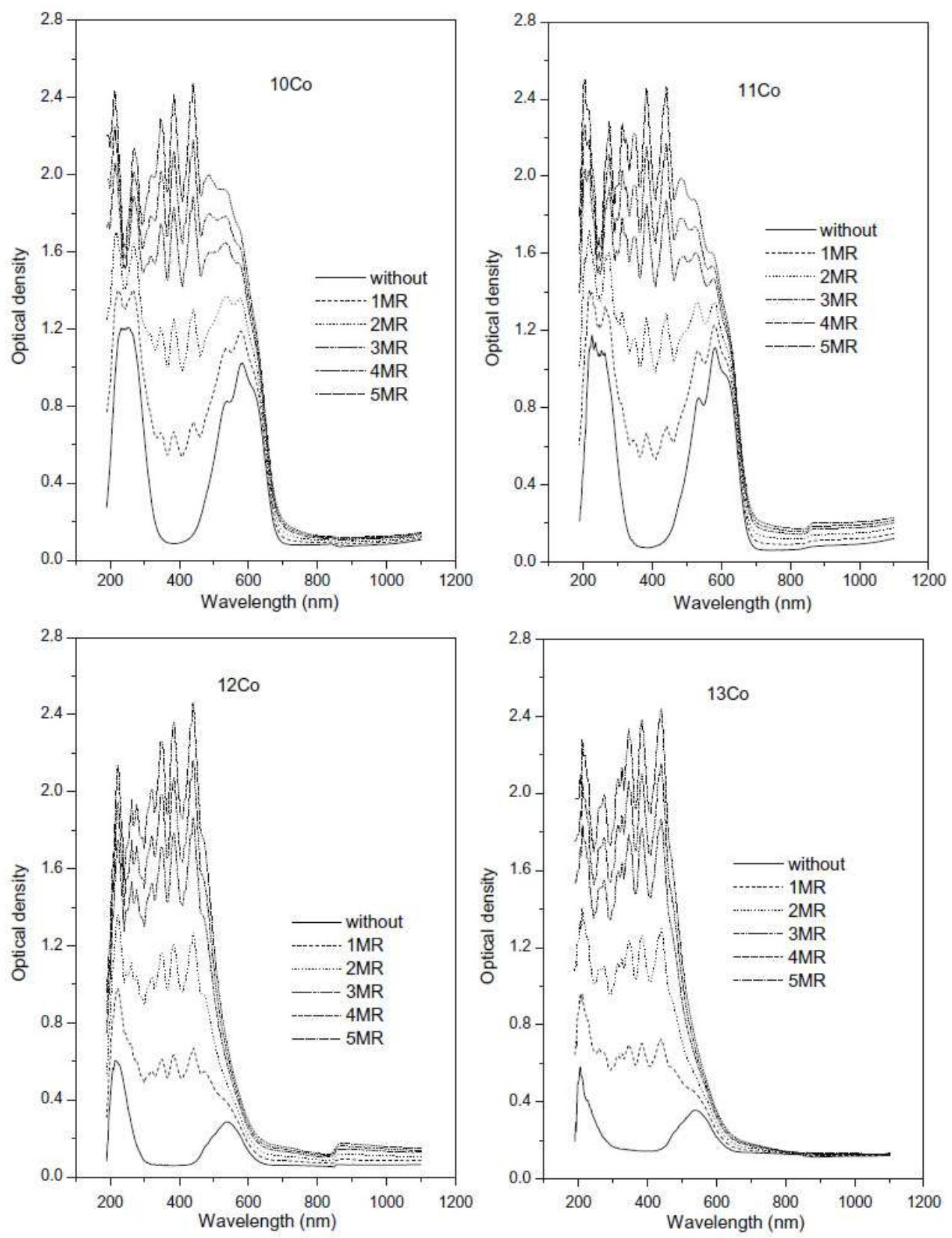

Fig. 7. Absorption spectra of CoO-doped sodium phosphate glasses with constant $0.25 \% \mathrm{CoO}$ with additional $5 \%$ or $10 \%$ of $\mathrm{Na}_{2} \mathrm{O}$ or $5 \%$ or $10 \% \mathrm{P}_{2} \mathrm{O}_{5}$ before and after gamma irradiation. 
the same gamma dose every time. Using a Fricke dosimeter, the absorbed dose in water was utilized in terms of dose in glass. No cavity theory corrections were made. Each glass sample was subjected to a total dose of $5 \times 104$ Gy (5MR). The UV-visible absorption of glasses containing $\mathrm{CoO}$-doped sodium metaphosphate glasses. The glass containing $0.05 \%$ $\mathrm{CoO}$ (glass/Co) reveals before gamma irradiation a strong ultraviolet charge transfer absorption with two small peaks at about 205 and $235 \mathrm{~nm}$ and the visible spectrum shows a small broad band centered at about $530 \mathrm{~nm}$. On subjecting this glass to successive gamma irradiation, the UV absorption progressively increases with marked splitting to three component peaks at about 205, 275, and $310 \mathrm{~nm}$ and followed by subsequent closelyconnected four peaks at about 340,400, 450, and $500 \mathrm{~nm}$. With glass containing higher concentrations $\mathrm{P} 0.5 \% \mathrm{CoO}$ ), the optical absorption spectra reveal the same strong ultraviolet absorption with two peaks at about 205 and $235 \mathrm{~nm}$ and the visible region shows a very broad band increasing in intensity with the increase of $\mathrm{CoO}$ content and exhibiting finally three small peaks at about 500,540, and $595 \mathrm{~nm}$. With continuous gamma irradiation, the absorption spectra reveal numerous connected peaks extending from 205 up to $400 \mathrm{~nm}$ exhibiting continuous growth with gamma irradiation and the distinct broad visible absorption is observed to be finally unaffected by progressive irradiation at high $\mathrm{CoO}$ content. The rate of increase with the first dose of irradiation is observed to be very high especially in the band at about $500 \mathrm{~nm}$ and the optical density is seen to be slowly increased with progressive irradiation.

\subsubsection{Condition of cobalt in glass}

Although cobalt can exhibit different oxidation states in many inorganic complexes but in glasses melted under normal atmospheric conditions, cobalt ion exists in the divalent state with two possible coordination forms, namely the octahedral and tetrahedral [Bates 1962, Bamford 1977, Paul 1990, Aglan 1955]; The only known ion having the $3 \mathrm{~d} 7$ configuration is $\mathrm{Co}^{2+}$. Early, Aglan 1955, and later other scientists [El-Batal,2003] have studied and interpreted the absorption spectra of glasses containing $\mathrm{Co}^{2+}$ in terms of equilibrium between octahedral and tetrahedral coordination forms of $\mathrm{Co}^{2+}$ ions depending on the type and composition of glass and condition of melting. The energy level diagram for $\mathrm{d} 7 \mathrm{system}$ in octahedral coordination predicts that the spectrum of $\mathrm{Co}^{2+}$ in octahedral symmetry will consist essentially of three bands corresponding to spin-allowed transitions ${ }^{4} \Gamma_{4} \rightarrow 4 \mathrm{C} 5$, ${ }^{4} \Gamma_{4} \rightarrow{ }^{4} \Gamma_{2}$ and ${ }^{4} \Gamma_{4} \rightarrow{ }^{4} \Gamma_{4}(\mathrm{P})$ together with several weak lines corresponding to spin-forbidden transitions. However, the band corresponding to the transition ${ }^{4} \Gamma_{4} \rightarrow 4 \Gamma_{2}$ is expected to occur only with low intensity as it corresponds to a forbidden two electron jump. Bates, 1962 has assumed that in low alkali glasses, $\mathrm{Co}^{2+}$ ions are present in octahedral symmetry probably with a rhombic distortion arising from the Jahn- Teller effect.

The energy diagram for $\mathrm{d} 7$ system in tetrahedral symmetry predicts that the spectrum of $\mathrm{Co}^{2+}$ in four coordination consists essentially of three bands [Sreekanth, 1998] corresponding to the spin-allowed transition ${ }^{4} \Gamma_{4} \rightarrow{ }^{4} \Gamma_{5},{ }^{4} \Gamma_{2} \rightarrow^{4} \Gamma_{4}$ and ${ }^{4} \Gamma_{2} \rightarrow^{4} \Gamma_{5}(\mathrm{P})$ together with several weak lines and bands corresponding to spin-forbidden transitions. The splitting of the $4 \Gamma 4(\mathrm{P})$ bands has been attributed to $\mathrm{L}, \mathrm{S}$ interactions (i.e. a departure from Russel-Sanders coupling) which is also quite large in the free ion. The high intensity of the tetrahedrally coordinated band is a consequence of the mixing of the 3d-orbitals with $4 \mathrm{P}$ orbitals and ligand orbital [ElBatal, 2008]. 


\subsection{Lead silicate glass}

Lead silicate and borate glasses glasses [El-Kheshen, A., 2008] have been extensively studied these last decades mainly because of their presence and importance in a broad range of technological applications. These glasses have been used in the electronic and optical technologies, such as for electron multiplier [Anderson,1979], micro-channel plated [Wiza, 1979], non-linear optical and magneto-optical devises [George, 1999]. Also, high lead silicate glasses can find application as radiation shielding materials [Friebele, 1991].

A base lead silicate glass of the chemical composition $\mathrm{PbO} 60 \mathrm{wt} \%, \mathrm{SiO}_{2} 40 \mathrm{wt} \%(71.24 \mathrm{PbO}$ $\mathrm{mol} \%, 28.76 \mathrm{SiO}_{2} \mathrm{~mol} \%$ ) was prepared by [Azooz , 2009] . Batches containing the base glass composition to which was added $0.1 \%$ of one of the 3d-transition metal oxides: $\mathrm{TiO}_{2}, \mathrm{~V}_{2} \mathrm{O}_{5}$, $\mathrm{Cr}_{2} \mathrm{O}_{3}, \mathrm{MnO}_{2}, \mathrm{Fe}_{2} \mathrm{O}_{3}, \mathrm{CoO}, \mathrm{NiO}$ or $\mathrm{CuO}$. An Indian 60Co gamma cell (2000 ci) was used as a gamma ray source with a dose rate of $1.5 \mathrm{~Gy} \mathrm{~s}-1$.

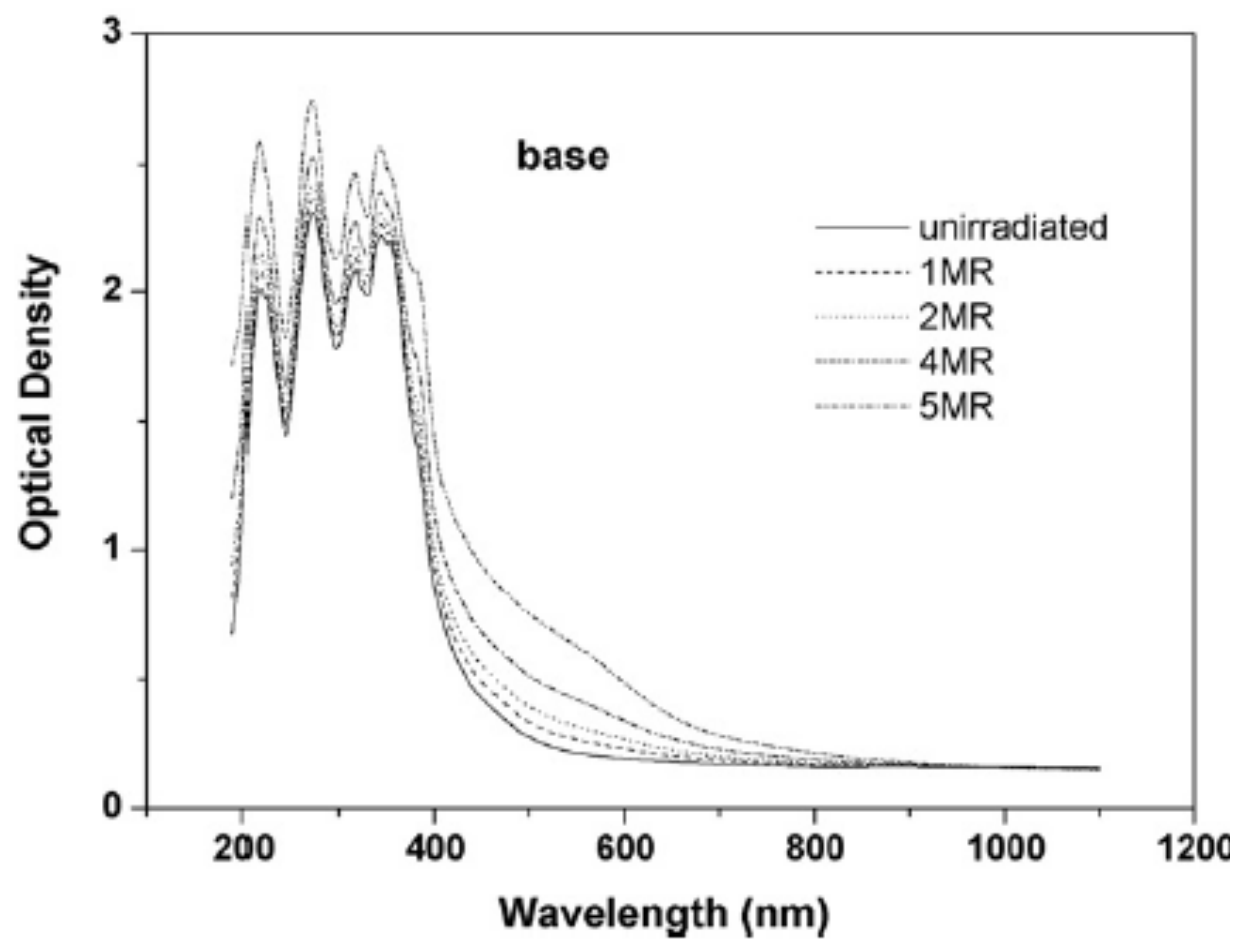

Fig. 8. The optical absorption spectra of the parent glass before and after different doses of gamma rays

Experimental results indicate that the effect of successive gamma irradiation is mainly concentrated in the changes of the intensities of the already observed UV bands which are 
assumed to be due to trace iron impurities (mainly $\mathrm{Fe}^{3+}$ ions) and to the $\mathrm{Pb}^{2+}$ ions. The main pronounced difference is the sharp growth of the kink at about 390nmto a pronounced peak and the quite resolution of a broad visible band centered at about $500 \mathrm{~nm}$. It seems that the presence of high content of the heavy metal oxide $(\mathrm{PbO})$, shows some shielding towards successive gamma irradiation and only limited changes are observed. This behavior is related to the presence of heavy $\mathrm{Pb}^{2+}$ ions which retard the movement or transfer of released electrons during the irradiation process [Singh, 2004].

The realization of the effect of gamma irradiation can be interpreted by assuming that when the lead silicate host glass is subjected to ionizing radiation, electron-hole pairs are produced, which then become individually trapped at various intrinsic defect sites in the glass structure. Also, the presence of trace iron impurities in the host glass can easily trap electrons or holes and further extrinsic defects may be formed by photochemical process. It has been shown by several authors [Bishay, 1977] that the principal feature of the spectra of $\mathrm{Pb}$ containing glasses is a band at $1.59 \mathrm{eV}$ with a width of $0.6 \mathrm{eV}$ which has been correlated with $\mathrm{Pb}^{3+}$ in silicate glasses. [Friebele, 1977] assumed that in oxide glasses this band is observed only when the $\mathrm{Pb}$ concentration is less than $\approx 25 \mathrm{~mol} \%$. A possible explanation for this is the assumption that $\mathrm{Pb} 2+$ is incorporated in glass as an ionic modifier for concentration of $\mathrm{PbO}$ $\leq 25-30 \mathrm{~mol} \%$, while at higher concentrations, $\mathrm{PbO}^{2+}$ is covalently bonded in $\mathrm{PbO}_{4}$ unit [Barker, 1965] and/or $\mathrm{PbO}_{3}$ unit [Fayon, 1999] as a glass former. [Friebele, 1991] further added that two bands with peak energies of 2.36 and $3.31 \mathrm{eV}$ are present in high lead glasses and can be associated with $\mathrm{Pb} 3+$ on a network forming unit. Regarding the $\mathrm{SiO} 2$ as a partner in the composition, [Bishay, 1977] and [Friebele 1991] have classified the origin of the UV induced bands and attributed them to electron centers while they related to the visible induced bands to positive holes. Later, [Shkrob, 2000] have assumed that irradiation of alkali silicate glasses results in the formation of metastable spin centers such as oxygen hole centers (OHC1 and $\mathrm{OHC} 2)$, silicon peroxy radicals and a silicon dangling electron center (E/center).

\subsection{1 $\mathrm{Cr}$ doped lead silicate glass}

This chromium-doped glass reveals before irradiation (Fig. 9) five strong ultraviolet absorption bands at about 205, 270, 310, 340 and 380nm followed by a strong visible band at about $440 \mathrm{~nm}$ and a medium band at about $480 \mathrm{~nm}$ and finally a very broad band centered at about $635 \mathrm{~nm}$. This observed spectrum represents collective presence of absorption bands due to trace iron impurities $(205,270,310 \mathrm{~nm}), \mathrm{Pb}^{2+}$ ions $(340 \mathrm{~nm})$ and hexavalent chromium ions $\mathrm{Cr}^{6+}(380 \mathrm{~nm})$ while the visible bands due to trivalent chromium bands (440 and 650 $\mathrm{nm})$ and a new mixed band $(470 \mathrm{~nm})$. These collective specific absorption bands are identified to the respective mentioned ions in various glass systems by several authors [Ghoneim, 1983].With progressive gamma irradiation, the six successive ultraviolet and near visible absorption bands slightly increase in intensity followed by slight increase and the presence of chromium ions seems to retard the effect of gamma irradiation this mentioned region. The visible band at about $470 \mathrm{~nm}$ shifts to longer wavelength at $480 \mathrm{~nm}$ while broad band highly increases in intensity and shifts from 650 to $620 \mathrm{~nm}$.

It can be assumed that some of the present $\mathrm{Cr}^{6+}$ ions capture liberated electrons during gamma irradiation and are converted to induced $\mathrm{Cr}^{3+}$ ions producing absorption in the same position of the trivalent chromium in the following photochemical reaction:

$$
\mathrm{Cr}^{6+}+3 \mathrm{e}^{-} \rightarrow \mathrm{Cr}^{3+}
$$




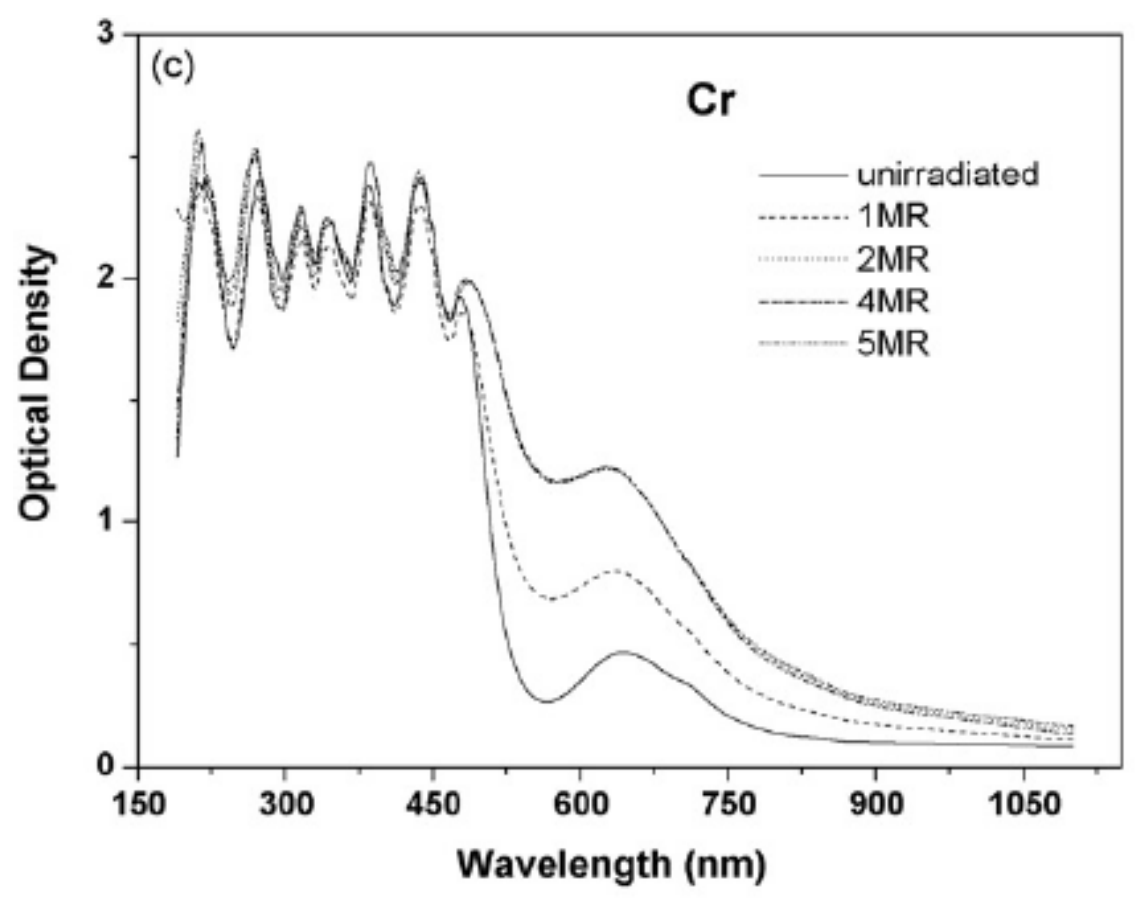

Fig. 9. The optical absorption spectra of the Cr-doped lead silicate glasses before and after different doses of gamma rays.

\subsection{Radiation processing for glass coloration / discoloration}

Glass is particularly susceptible to radiation-induced coloration/ discoloration due to its amorphous, non-crystalline structure. The nature of the optical changes varies, but usually consists of coloration in the visible light region and the formation of absorption bands in the infrared and/or ultraviolet regions. The optical density is almost always increased. It is well documented, for example, that high doses of gamma radiation turn glass various shades ranging from deep brown to pale amber [Prasil, 1991]. Clear glass discolors when exposed to gamma irradiation, such as from a Cobalt-60 source. Ordinary flint, borosilicate, and lead glass undergo a color change from clear to light amber, brownish to black, depending on the amount of energy absorbed. Milk glass, when exposed to gamma irradiation, yields a grayish color, depending on energy absorbed and any swirling effect is highlighted, probably due to concentrations of color in the glass that have not mixed uniformly. The actual mechanism of the formation of "color centers" has been described [Prasil, 1991]. The final color created is dependent on the chemical composition of the glass and can be altered by selection of additives (e.g., cerium ions can reduce browning; manganese ions induce an 
amethyst color). Final color is a combination of original glass color and the effects of color center formations.

Color from irradiation is considered metastable and heat, for example, is known to reverse the effect. Depending on the type of color centers formed and the hardness of the glass, varying amounts of heat or energy penetration are required to reverse color. Glass with a low diffusion rate (high softening point) is more stable. Combining all of these factors gives a very unique decorative coloration to a glass item. Very striking color contrasts can evolve, depending upon the color of the paints utilized on an item, the chemical composition, and impurities in the glass. At low doses, the color intensity increases linearly but eventually saturates at high doses. The final product is not radioactive or contaminated in any sense.

The general physical properties of colored glass include:

1. Color stability: There is a slight loss of color during the first several days after processing, and thereafter the rate of fade is slight. The process can actually be reversed, causing the glass to become clear, by placing the unit in an oven at approximately $300^{\circ} \mathrm{F}$ for a couple of hours. Hence, for applications where the product is exposed to high heat or low heat on a routine basis (e.g., dishwashers), this may not be ideal.

2. Ultraviolet absorption: There is a small amount of ultraviolet absorption characteristic which changes as the glass is further discolored.

3. Physical properties: Other than the color change, the normal physical properties of glass are not affected [Dietz 1976, Prasil, 1990].

The advantages of irradiation for decorative glass coloration include:

1. Processing is done in shipping carton. There is no need to unpack or handle individual pieces.

2. The process is simple, clean, and completely safe to the end product and to the consumer.

3. Although economics would tend to favor large volumes, smaller volumes can also be economically attractive. The irradiation process is not dependent on processing large runs.

4. There is no waste product or breakage associated with the process

\section{Colored glass as radiation sensor [Dunn, T.M. 1960]}

This wonderful material (colored glass), with its beautiful appearance, has another use rather than decoration which is: radiation sensor. Some other instruments were used as radiation detectors but now colored glass has the same action, due to transition elements doping in glass. There are a number of properties shared by the transition elements that are not found in other elements, which results from the partially filled $d$ shell. These include:

- The formation of compounds whose color is due to $d$ - $d$ electronic transitions

- The formation of compounds in many oxidation states, due to the relatively low reactivity of unpaired $d$ electrons.

- The formation of many paramagnetic compounds due to the presence of unpaired $d$ electrons. A few compounds of main group elements are also paramagnetic (e.g. nitric oxide, oxygen). 
Color in transition-series metal compounds is generally due to electronic transitions of two principal types.

Charge transfer transitions. An electron may jump from a predominantly ligand orbital to a predominantly metal orbital, giving rise to a ligand-to-metal charge-transfer (LMCT) transition. These can most easily occur when the metal is in a high oxidation state. For example, the color of chromate, dichromate and permanganate ions is due to LMCT transitions. Another example is: Mercuric iodide, $\mathrm{HgI}_{2}$, is red because of a LMCT transition. As this example shows, charge transfer transitions are not restricted to transition metals. A metal-to ligand charge transfer (MLCT) transition will be most likely when the metal is in a low oxidation state and the ligand is easily reduced. $d$ - $d$ transitions. An electron jumps from one d-orbital to another. In complexes of the transition metals the $d$ orbitals do not all have the same energy. The pattern of splitting of the $d$ orbitals can be calculated using crystal field theory. The extent of the splitting depends on the particular metal, its oxidation state and the nature of the ligands. In octahedral complexes, $d-d$ transitions are forbidden and only occur because of coupling in which a molecular vibration occurs together with a $d$ - $d$ transition. Tetrahedral complexes have somewhat more intense color because mixing $d$ and $p$ orbitals is possible when there is no centre of symmetry, so transitions are not pure $d$ - $d$ transitions. The molar absorptivity $(\varepsilon)$ of bands caused by $d-d$ transitions are relatively low, roughly in the range $5-500 \mathrm{M}^{-1} \mathrm{~cm}^{-1}$ (where $\mathrm{M}$

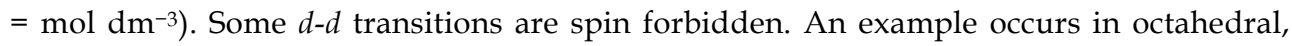
high-spin complexes of manganese (2), which has a $d^{5}$ configuration in which all five electron has parallel spins; the color of such complexes is much weaker than in complexes with spin-allowed transitions. In fact many compounds of manganese (2) appear almost colorless. The spectrum of $\left[\mathrm{Mn}\left(\mathrm{H}_{2} \mathrm{O}\right)_{6}\right]^{2+}$ shows a maximum molar absorptive of about $0.04 \mathrm{M}^{-1} \mathrm{~cm}^{-1}$ in the visible spectrum.

A characteristic of transition metals is that they exhibit two or more oxidation states, usually differing by one. Main group elements in groups 13 to 17 also exhibit multiple oxidation states. The "common" oxidation states of these elements typically differ by two. For example, compounds of gallium in oxidation states +1 and +3 exist in which there is a single gallium atom. No compound of $\mathrm{Ga}(2)$ is known: any such compound would have an unpaired electron and would behave as a free radical and be destroyed rapidly. The only compounds in which gallium has a formal oxidation state of +2 are dimeric compounds, such as $\left[\mathrm{Ga}_{2} \mathrm{Cl}_{6}\right]^{2-}$, which contain a $\mathrm{Ga}-\mathrm{Ga}$ bond formed from the unpaired electron on each $\mathrm{Ga}$ atom. Thus the main difference in oxidation states, between transition elements and other elements is that oxidation states are known in which there is a single atom of the element and one or more unpaired electrons. The maximum oxidation state in the first row transition metals is equal to the number of valence electrons from titanium (+4) up to manganese (+7), but decreases in the later elements. In the second and third rows the maximum occurs with ruthenium and osmium (+8). In compounds such as $\left[\mathrm{MnO}_{4}\right]^{-}$and $\mathrm{OsO}_{4}$ the elements achieve a stable octet by forming four covalent bonds. The lowest oxidation states are exhibited in such compounds as $\mathrm{Cr}(\mathrm{CO})_{6}$ (oxidation state zero) and $\left[\mathrm{Fe}(\mathrm{CO})_{4}\right]^{2-}$ (oxidation state -2 ). These complexes are also covalent. Ionic compounds are mostly formed with oxidation states +2 and +3 . In aqueous solution the ions are hydrated by (usually) six water molecules arranged octahedrally. 


\subsection{Why do many glasses turn green, brown or black when exposed to ionizing radiation? [El-Kheshen A. A., 1999]}

The phenomenon of radiation-induced color change is called 'activation of color centers'. The details are quite complex and involve an alteration of the orbital distribution of an atom's valence (outermost) electrons, causing the atom to absorb photons of a different frequency (color) after irradiation than before. What we describe as the reflected, transmitted, and emitted colors of a material is a consequence of the outermost shell of electrons, the valence electrons of atoms. In the following discussion, we will consider primarily reflected light.' White' light is actually a mixture of photons of many different frequencies (colors), and color is typically described by wavelength. The valence shell of an atom, described by classical physics as comprised of up to eight discreet electrons, is described by quantum physics to behave as a singular 'thing'. The valence shell will resonate with (it will capture, or absorb) photons of certain discrete energies. This resonance causes the valence shell to become excited, or 'pumped', to a higher energy meta-stable 'level' or state. The atom has a 'ground' (un-excited) state, and may have multiple excited states. Upon absorption of radiation of energy, electrons may be stripped from the atom, resulting in multiple degrees of ionization, each capable of multiple states of excitation. For example, a hypothetical atom with eight electrons in its valence shell has its ground state and shall have three meta-stable excited states. Upon capture of a photon of energy, one of the valence electrons is stripped resulting in the atom becoming a singly-ionized ion. This particular ion shall have two meta-stable excited states, and upon capture of a photon of energy a second of the valence electrons is stripped resulting in a doubly-ionized ion capable of four metastable states. And so on. For any mono-atomic atom, and for the shared valence electron orbitals of any compound, there are these discreet states capable of absorbing (and emitting) discreet quanta of energy which is shuttled around as photons. Now, let's work with a real example: Let's assume that we have a 'white' light beam composed of red, blue and yellow photons (the primary transmissive colors). We direct this beam onto a puddle of red anthracine dye. Anthracite dyes have tri-cyclic ('aromatic') structures which are capable of resonating with discreet spectra of frequencies [El-Batal, 2008]. By slight modifications of their molecular structures the valence orbitals of their constituent carbon atoms can be altered, which results in slightly different resonant characteristics. The different anthracine dyes thus appear to our eyes as having different colors. We have selected a red one. The blue and yellow photons in our white light resonate with (are captured and absorbed by) the red dye molecule, and the red photons are scattered (reflected). Some of this scattered red light is directed toward our eyes, and we thus see the puddle of dye as 'red'. If we put the puddle of red dye on a clear film, the red photons will be seen also to pass through the dye.

Now, let's examine a piece of colored glass. The materials which are added to glass as pigments are selected because their valence shell electrons are capable of selectively absorbing photons of certain frequencies, while passing and reflecting others. Cobaltic oxide for example, will absorb red and yellow but not blue, thus cobalt glass is blue. Transparent glasses in general are a mixture of alkaline and transition metal oxides, most of which are selected precisely because they won't interact with visible light. Put a piece of such a transparent glass in a high neutron-flux or high radiation (such as $\gamma$-ray) environment, and they will 'become colored' as the glass becomes physically altered at the atomic level [Moustafa , 2010 ]. 


\subsection{Can the activation of color centers be reversed? Can the colored glass be made clear again? [Radek, 2009]}

Yes. Glass, even at room temperature, is a liquid: the interatomic bonds are weak and constantly breaking and reforming. These bonds are in fact an interaction of (or, sharing of) the valence electrons of adjacent atoms. (In metals this sharing of electrons results in electrical conduction. For example, in a length of copper wire, the individual electrons at one end of the wire will, in theory, eventually migrate to the other end of the wire, due to random motion and without the application of an outside force). The inter-atomic bonding structure within the bulk of a material places physical constraints upon the valence electrons. Therefore, if you activate a color center (by any means) the alteration in the valence shell will be either stable (unchanging with time) or meta-stable (will change gradually with time). The stronger the interatomic structure (or 'lattice' in the case of a true crystal which, unlike a glass, is a solid) the more stable the change. The change can however be reversed by weakening the inter-atomic bonds which will allow the formation of new, lower energy bonds (atoms will break their initial bonds and reform bonds with other neighbors). This can be accomplished simply by the application of heat. In practice, the temperature required for complete color deactivation in an amorphous material (such as a glass) is its annealing temperature. Therefore, simply annealing a piece of glass will deactivate the color centers. Having worked extensively with researchers who conduct experiments which activate color centers by both of these means, I have frequently had need to deactivate color centers. An unexpected consequence of color center activation is the formation of strained inter-atomic bonds, and unless the piece is annealed, it may spontaneously fracture! As a rule, the more a piece is colored, the more strain the piece is under, and the more it needs to be annealed. Note that the color doesn't 'cause' the strain. Rather, color and strain are two entirely separate issues sharing the same cause. Finally, it's worth pointing out that color center activation is now so well understood that unusually colored gemstones are now being created by the process. In some cases, semiprecious irradiated stones are fraudulently sold as precious gem stones, and the difference can only be distinguished by a professional gemologist. Many materials when exposed to radiation will darken or change color. For example you can occasionally find a discarded bottle that had been left outside for many years that has become darkened due to exposure to sunlight. Co-60 emits gamma rays, which are light waves but with a much higher energy than visible light. Many hospitals use a Co-60 source to sterilize medical supplies after they have been packaged. So why does gamma radiation change the color of glass? We need to look at the structure of glass and at why certain materials absorb different colors of light to understand the effect. Glass is made of silicon and oxygen. Oxygen atoms are hungry for more electrons than they are naturally given, so each oxygen atom will share an electron from the silicon atom. This shared electron creates a very strong attraction between the oxygen and silicon, and is the reason why glass is a very hard material.

As you can tell by looking out a window, visible light goes right through glass. For light to be absorbed in a material, the light wave has to interact with an electron in the material and basically "shake it loose" from its atom. In glass the electrons are so tightly held by the silicon and oxygen atoms that visible light cannot shake one of those electrons loose, so light travels right through without any absorption. But gamma rays, which have a million times as much energy as visible light, can shake a lot of things loose in glass. When a gamma ray enters glass, it can actually knock a silicon atom out of its place, shoving it in-between other 
atoms, and leaving a hole, or vacancy, in the material. The electrons surrounding the hole will no longer be tightly bound to the atoms, and these "loose" electrons will be able to interact with lower energy light (visible light). When visible light is transmitted through the glass, specific colors of the light can interact and be absorbed by the electrons near the vacancy, and the transmitted light will have a color that is the complement of the absorption. These holes, or defects, are often called "color centers" because they impart a color to the glass. If you heat the irradiated glass (called annealing) the atoms will begin to shake so much that the displaced silicon atom will eventually go back to its original place and the glass will become clear again.

\section{References}

Aglan, M.A., Moore, H., J. Soc. Glass Technol. 39 (1955) 35 T.

Anderson, L.P., Grusell, E., Berg, S., J. Phys. E 12 (1979) 1015.

Arbuzov, V. Belyankina, N.,"Spectroscopic and photochemical properties of cerium in silicate glass", Fiz. Khim. Stekla 16 (1990) 593-604.

A world of glass, http://www.britglass.org.uk/Index.html.

Azooz, M.A., El-Batal, F.H., " Gamma ray interaction with transition metals-doped lead silicate glasses", Materials Chemistry and Physics 117 (2009) 59-65.

Barker, R.S., McConckey, E.A., Richardson, D.A. Phys. Chem. Glasses 6 (1965) 24-29.

Bates, T., in: D. Mackenzie (Ed.), "Modern Aspects of the Vitreous State", vol. 2, Butterworth, London, 1962, p. 195.

Bamford, C.R., "Colour Generation and Control in Glass", Elsevier, New York, 1977.

Bishay A. Radiation induced color centers in multicomponent glasses. J Non-Cryst Solids 1970;3:54-114.

Bishay, A., Maklad, M. ,Phys. Chem. Glasses 7 (1966) 149-156.

Dietz, George R., “Radiation Coloring of Glass” Presentation to Society of Glass Decorators, Annual Meeting October 11- 13, 1976, Pittsburgh, PA.

Dunn, T.M., Wilkins, R.G. "Modern Coordination Chemistry. New York: Interscience., Chapter 4, Section 4, "Charge Transfer Spectra", pp. 268-273, 1960.

El-Batal, F., Ouis, M., Morsi, R. Marzouk, S.," Interaction of gamma rays with some sodium phosphate glasses containing cobalt", Journal of Non-Crystalline Solids 356 (2010) 46-55.

ElBatal, F.H., ElKheshen, A.A., Azooz, M.A., Abo-Naf, S.M., Opt. Mater. 30 (2008).

El-Batal,. Khalil, M.M.I, Nada, N., Desouky, S.A. Mater. Chem. Phys. 82 (2003) 375.

El Kheshen, A. A. El-Batal, F., Marzouk,S."UV-visible, Infrared and Raman spectroscopic and thermal Studies of tungsten doped lead borate glasses and the effect of ionizing gamma irradiation", Indian Journal of Pure \& Applied Physics, 46, 4, 225 238, 2008.

El-Kheshen, A. A., "Effect of $\gamma$ - rays on some glasses containing transition metals, A PhD thesis, Ain-Shams University, Egypt, 1999.

Fayon, F., Landron, C., Sakwari, K., Bessada, C., Massiot, D., J. Non-Cryst. Solids 243 (1999) 39.

Friebele EJ. Radiation effects in optical and properties of glass. New York, Westerville; 1991. 
Friebele, E.J. in: D.R. Uhlmann, N.J. Kreidl (Eds.), Optical Properties of Glasses, The American Ceramic Society,Westerville, OH, 1991, p. 205.

Friebele, E.J. Proc. Int. Congr. Glass, 11th, Progue, vol. 3, 1977, pp. 87-95.

George, H.B., Vira, C., Stehle, C. , J. Meyer, S. Evers, D. Hogon, S. Feller,M. Affatigato, Phys. Chem. Glasses 40 (1999) 326.

Ghoneim, N.A., El-Batal, H.A., Zahran, A.H., Ezz ElDin, F.M. Phys. Chem. Glasses 24 (1983) 83.

Gerry, M., Alan M., "Glass: a world history, published by; University of Chicago Press", 2002.

Gusarov, A., Huysmans, S., Berghmans, F., "Induced optical absorption of silicate glasses due to gamma irradiation at high temperatures", Fusion Engineering and Design 85 (2010) 1-6.

Jiawei S, Yanfen W, Xinji Y, Jian Z., "UV-laser irradiation on the soda-lime silicate glass", International Journal of Hydrogen Energy, 34 ( 2009 ) 1123 - 1125.

Marshall CD, Speth JA, Payne SA. Induced optical absorption in gamma, neutron and ultraviolet irradiated fused quartz and silica. J Non-Cryst Solids 1997;212:5973.

Moustaffa, F.A., El-Batal, F.H., Fayad, A.M., El-Kashef, I.M.Absorption Studies on Some Silicate and Cabal Glasses Containing $\mathrm{NiO}$ or $\mathrm{Fe}_{2} \mathrm{O}_{3}$ or Mixed $\mathrm{NiO}+\mathrm{Fe}_{2} \mathrm{O}_{3}$ ", Acta physica polonica A, Vol. 117, 2010.

Noel, C.,S., "The Glass and Glazing Handbook; Standards Australia, “SAA HB125-1998.

Paul, . A. Chemistry of Glasses, second ed., Elsevier, New York, 1990.

Prasil, Z , Marlind, T. "Two colors out of one" Glass Decoloration \#125, beta-gamma, 1991, 2-3.

Prasil, Z. and Marlind, T. "Radiation Coloration of Glass-State of the Art, Glass Decoloration \#249, beta-gamma 1991, 2-3.

Prasil, Z., Schweiner, E., Pesek, M. "Radiation Modification of Physical Properties of Inorganic Solids", Radiation Physics and Chemistry, Vol. 35, Nos. 4-6, pp.509-513, 1990.

Radek , P. Vojtěch E., Viktor G., Mariana K., Martin M., Ondřej, S., Ladislav S., " A comparison of natural and experimental long-term corrosion of uranium-colored glass", J. of Non-Crystalline Solids, Volume 355, Issues 43-44, , Pages 2134-2142, 2009.

Sheng J., "Photo-induced and controlled synthesis of Ag nanocluster in soda-lime silicate glass". Int J Hydrogen Energy 2007;32(13). 2062-65.

Sheng J, Li J, Yu J. The development of silver nanoclusters in ion-exchanged soda-lime silicate glasses. Int J Hydrogen Energy 2007;32(13):2598-601).

Shkrob, I.A., Tadjikov, B.M., Trifunac, A.D. J. Non-Cryst. Solids 262 (6) (2000) 35.

Singh, N., Singh, K.J., Singh, K., Singh, H., Nucl. Instrum.Methods Phys. Res., B 255 (2004) 305.

Sreekanth , R.P., Murali, A., Lakshmara Rao, J. J. Alloy. Compd. 281(1998) 99.

Weyl, W.A "Coloured Glasses, reprinted by Dawsons of Pall Mall, London, 1959.

Wiza, J.L. Nucl. Instrum. Methods 62 (1979) 587.

Wong J, Angell CA. Glass: structure by spectroscopy. NewYork: Marcel Dekker; 1976. 
Zhang J, Dong W, Qiao L, Li J, Zheng J, Sheng J. Silver nanocluster formation in the sodalime glass by X-ray irradiation and annealing. J Cryst Growth 2007;305:278-84 


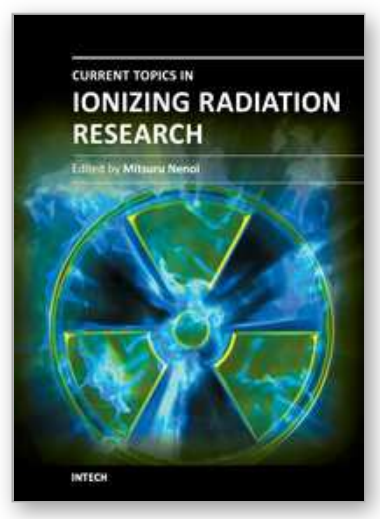

\author{
Current Topics in lonizing Radiation Research \\ Edited by Dr. Mitsuru Nenoi
}

ISBN 978-953-51-0196-3

Hard cover, 840 pages

Publisher InTech

Published online 12, February, 2012

Published in print edition February, 2012

Since the discovery of $X$ rays by Roentgen in 1895 , the ionizing radiation has been extensively utilized in a variety of medical and industrial applications. However people have shortly recognized its harmful aspects through inadvertent uses. Subsequently people experienced nuclear power plant accidents in Chernobyl and Fukushima, which taught us that the risk of ionizing radiation is closely and seriously involved in the modern society. In this circumstance, it becomes increasingly important that more scientists, engineers and students get familiar with ionizing radiation research regardless of the research field they are working. Based on this idea, the book "Current Topics in lonizing Radiation Research" was designed to overview the recent achievements in ionizing radiation research including biological effects, medical uses and principles of radiation measurement.

\title{
How to reference
}

In order to correctly reference this scholarly work, feel free to copy and paste the following:

Amany A. El-Kheshen (2012). Glass as Radiation Sensor, Current Topics in lonizing Radiation Research, Dr. Mitsuru Nenoi (Ed.), ISBN: 978-953-51-0196-3, InTech, Available from:

http://www.intechopen.com/books/current-topics-in-ionizing-radiation-research/glass-as-radiation-sensor

\section{INTECH}

open science | open minds

\section{InTech Europe}

University Campus STeP Ri

Slavka Krautzeka 83/A

51000 Rijeka, Croatia

Phone: +385 (51) 770447

Fax: +385 (51) 686166

www.intechopen.com

\section{InTech China}

Unit 405, Office Block, Hotel Equatorial Shanghai

No.65, Yan An Road (West), Shanghai, 200040, China

中国上海市延安西路65号上海国际贵都大饭店办公楼 405 单元

Phone: +86-21-62489820

Fax: +86-21-62489821 
(C) 2012 The Author(s). Licensee IntechOpen. This is an open access article distributed under the terms of the Creative Commons Attribution 3.0 License, which permits unrestricted use, distribution, and reproduction in any medium, provided the original work is properly cited. 